TRANS $\cdot$ núm. I3 $\cdot 2009$

ARTICULOS · 197-214
Victor Klemperer (1881-1960) reunió en LTI. Notizbuch eines Philologen sus ideas sobre el uso manipulador y propagandista que del idioma alemán se hiciera durante el Tercer Reich. En esta obra Klemperer examinó los cambios sutiles pero manifiestos, operados en el lenguaje en conjunto, así como en términos específicos, durante la época de referencia. Este trabajo introductorio estudia algunas características de la traducción al castellano (2001) de LTI por Adan Kovacsics, quien se decide mayormente por la variante de traducción conocida como "expuesta». Nos concentramos por igual en los aspectos culturales y en los lingüísticos. Repasamos, entre otros aspectos relevantes, la traducción del lenguaje figurado, la intensificación y atenuación del original, y la transferencial presencia de la ironía en la traducción.

PALABRAS CLAVE: lenguaje del nacionalsocialismo, traducción "expuesta", traducción del lenguaje figurado, intensificación y atenuación del original, ironía

\title{
Tropos, circunvoluciones e ironía: sobre la traducción al español de LTI. Notizbuch eines Philologen, de Victor Klemperer
}

Eloy E. Merino \&t Katharina Barbe Universidad de Northern Illinois
Victor Klemperer (1881-1960) collected in LTI. Notizbuch eines Philologen his observations of the manipulative and propagandist language usage during the Third Reich. He examined subtle, yet noticeable changes in the language as a whole as well as in specific words. To function as an introduction to Klemperer's work, this essay studies some issues in Adan Kovacsics' 2001 translation into Spanish. Kovacsics chose an overt translation which invokes the original context. We concentrate on the cultural as well as on the linguistic aspects of the translation. Primarily, we review the translation of Klemperer's figurative language, as well as the process of ennoblement and impoverishment of the original, the transference/presence of the irony of the original, and other relevant issues.

KEYWORDS: language of National Socialism, overt translation, translation of figurative language, ennoblement and impoverishment of the original, irony. 


\section{INTRODUCCIÓN}

En 200I apareció la versión española de LTI. 198
Notizbuch eines Philologen de Victor Klemperer (I88I-I960), y la de sus diarios en 2003. Este tipo de literatura sobre las interioridades del totalitarismo alemán ofrece a los estudiosos y al público en general «una fuente excepcional para el estudio de la vida cotidiana y de la persecución de los judíos» (Moreno León, s.d.). Libro con información de primera mano, que responde al interés tradicional que despierta todo lo relacionado con la Alemania nazi en los países de habla española. La versión de LTI (Lingua Tertii Imperii) fue realizada por Adan Kovacsics, traductor especializado en autores germanos y húngaros (Thomas Bernhard, Heinrich Böll, Max Weber, György Konrad, entre otros).

La reacción de cualquier lector ante una traducción depende del contexto histórico, del orden de sus expectativas, del momento social y de la distancia emocional entre su persona y los eventos que se narran o se ilustran. Es dable pensar que el lector de habla española recibe los comentarios de Klemperer, traducidos, en un contexto y en un momento social muy disímiles del alemán; de forma más inocente, si se permite. Es ese lector genérico un espectador desfasado, en 2001 o en 2003 , de los acontecimientos, no un personaje (o un descendiente de éste) sobre el escenario. Su distancia emocional es mucho más grande que la del público alemán; es casi neutra. No influyen en este lector el trasfondo cultural, la experiencia vital, la proximidad consaguínea y la culpa histórica que pueden teñir la recepción del lector germano ${ }^{\mathrm{I}}$. Paradójicamente, LTI puede ser para aquel una obra histórica, didáctica e, incluso, de solaz, de

I Para la historia y evolución de las diversas impresiones en alemán, y para la recepción del libro en las dos Alemanias, antes de la reunificación, v. K. Fischer-Hupe (200I). esparcimiento mental, como si estuviese leyendo una fantasía narrativa sobre un país hechizado y atormentado por brujos satánicos.

La brillantez del análisis de Klemperer y la vigencia implícita de su comentario, por analogía, en un mundo donde los totalitarismos son comunes - en los sesenta y tantos años que han transcurrido desde la conclusión de la Segunda Guerra Mundial-, prestan urgencia y sorprendente actualidad a su obra. Según Duanel Díaz (s.d.), el libro de Klemperer no estudia un "pasado perfecto sino un presente arrasador que viene al encuentro del filólogo». En el ámbito de lengua española han tenido y tienen lugar varios códigos lingüísticos que recuerdan la intención y los mecanismos del idioma «imperial» nazi, desde la argumentación del franquismo/falangismo español hasta la de las dictaduras latinoamericanas más feroces, y por ello más necesitadas de una especial retórica vindicatoria, como la propiciada por el régimen de Pinochet en Chile para justificar su represión contra el estudiantado y la disidencia general. O en la Argentina de las juntas militares (19761983) para desentenderse de su culpabilidad en la desaparición de miles de argentinos ${ }^{2}$.

El presente trabajo, motivado por las premisas anteriores, se enfoca en la traducción al español de LTI y pasa a analizar varios de los mecanismos que posibilitan, o no, la efectivi-

2 Andrea Benites-Dumont (s.d.) recuerda que en el país austral «durante los monstruosos años de la dictadura genocida, el léxico que establecieron los militares era el correlato lingüístico al plan de amputación social, el mandato terrorífico de ocultar la realidad o de imponer una fraudulenta visión de la misma. Así se impuso el eufemismo de llamar 'proceso de reorganización nacional' al plan de exterminio. Indujeron un vocabulario elemental pero dotado de una potencia aterradora - como fuera en su momento la solución final en el nazismo- durante la dictadura argentina los desaparecidos operaron socialmente de igual modo» (el subrayado en el original). 
dad y la pertinencia del mensaje de Klemperer para los lectores de habla castellana. Con tal fin hemos estructurado el repaso de la versión de Kovacsics en base a los siguientes elementos: la presencia de traducción "expuesta» (overt translation), la traslación del lenguaje figurado, de los clichés, la intensificación de la traducción, o su reverso, la atenuación, la traducción de los diálogos, y la transferencia de la ironía en el original. Todos los anteriores son, a nuestro juicio, componentes relevantes en la intención e impacto del texto de Kovacsics, y a la vez reflejan, directa o indirectamente, aquéllos que estructuran, en palabras de Roderick Watt (1998: 360), ese influyente y controvertido estudio sobre la influencia de la ideología nazi en el idioma alemán, el original. Haremos una selección de los pasajes en la traducción que nos parecen más ilustrativos de los temas mencionados, y los acompañaremos de nuestras reflexiones al respecto.

\section{EL CONTEXTO ORIGINAL DE LTI. NOTIZBUCH EINES PHILOLOGEN}

De profesión filólogo en lenguas romances y catedrático especializado en literatura francesa del XVIII, Victor Klemperer compiló sus observaciones sobre el carácter artificioso y mixtificador del peculiar lenguaje nazi, institucionalizado en Alemania entre 1933 y 1945, en este libro que publicó en I947. Aunque sufriera vejaciones y maltrato bajo el régimen, Klemperer, judío convertido al protestantismo, consiguió sobrevivir a la pesadilla del Tercer Reich porque se había matrimoniado en 1906 con una «aria», la pianista Eva Schlemmer, y por ello disfrutó de una salvaguardia indirecta, concedida por las autoridades nazis a partir de la legislación relativa a los «matrimonios mixtos» («Mischehen») ("«Nota del editor»: viii). La pareja Klemperer tenía la categoría de «nicht-privilegierte» («no privilegiado»), matrimonio mixto donde el hombre era judío y la mujer no (Michael, 2002: 276-7). La escritura de sus diarios (de la que $L T I$ es parte) se convirtió para Klemperer en una especie de salvación espiritual, «un balancín del que se sujeta[ba]» $(\mathrm{K}, 24)^{3}$, una salida a su creatividad erudita y humanista, ahora suprimida a la fuerza por el poder, después que fuera desposeído de su cátedra en mayo de 1935 (2003: 244).

En el prefacio al libro, que tituló «Heroísmo», Klemperer relata cómo le llamase la atención que sus compatriotas después de terminada la guerra se aferraran a argumentos del nazismo, «con toda inocencia y en un esfuerzo sincero por remediar lagunas y errores de formación» (K, I2-3) [ «wie die jungen Leute in aller Unschuld, und bei aufrichtigem Bemühen, die Lücken und Irrtümer ihrer vernachlässigten Bildung auszufüllen», 8]. No se dan cuenta los jóvenes, pero ponen de nuevo en circulación «usos lingüísticos heredados de la época anterior» $\left(\mathrm{K}, \mathrm{I}_{3}\right)$ [«der beibehaltene Sprachgebrauch der abgelaufenen Epoche», 8], los cuales confunden y que, además, los han seducido a su pesar. Klemperer observa, con alarma y cierta tristeza, cómo todas aquellas mentes frescas, $\mathrm{y}$ con la mejor voluntad, hablaban del sentido de la cultura, del humanismo, de la democracia, y «de repente, de forma inevitable», comenzaban a manejar términos cuya densa carga connotativa ignoraban. En el preciso instante, escribe, que estos conceptos entraban «mínimamente en juego, la claridad desaparecía y volvíamos a meternos de lleno en los nubarrones del nazismo» [«und wir staken wieder tief im Gewölk des Nazismus», 8]. Preocupado, Klemperer

3 En lo adelante nos referiremos a la traducción de A. Kovacsics con una «K» seguida de la página de referencia. Las citas del original en alemán (LTI. Notizbuch eines Pbilologen) tendrán solamente el número de página.

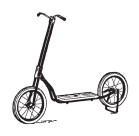

199 
consigna que no puede el pueblo alemán establecer una relación realmente adecuada con la esencia del humanismo, de la cultura y de la democracia, cuando sus ciudadanos manejan erradamente en 1946 los conceptos abstractos del régimen anterior, en los cuales basan de manera ingenua esos anticipados grandes ideales (K, I3). Por ello se afana Klemperer en componer este libro, un aviso y un recordatorio, para que las «distorsiones y exterioridades» (K, 20) [«Verzerrungen und Veräußerlichungen», I3] del nazismo no se atrincheren en la psiquis y en la lengua alemanas, y vicien la reconstrucción cultural e ideológica nacionales. No escribirá Klemperer su libro por vanidad, sino «más bien por ciertas palabras» $(\mathrm{K}, 4 \mathrm{IO})$ [«als wejen Ausdrücken», 300], inofensivas en apariencia, pero en realidad dosis de arsénico retórico $(\mathrm{K}$, 3I). Katharina Barbe (2007: 505, 510) arguye que en la motivación de la protesta textual de Klemperer reside una metáfora: «Propaganda is a poisonous jargon», lo que también explica su gran influencia, en el sentido de que es letal, y es accesible al pueblo, además.

\section{TRADUCCIÓN 'EXPUESTA'}

La traducción de LTI ha de vérselas con un doble tamiz: Klemperer a menudo ha de interpretar o «traducir» para su lector la jerga nazi, y Kovacsics, en consecuencia, habrá de traducir al traductor, por así decirlo; no querrá ocultar la naturaleza del texto que produce, una traducción «expuesta» (overt translation, House, 2006: 347), revelada en la decisión por Kovacsics de acompañar muchas de sus soluciones con el original en corchetes, o viceversa, y anunciarlo en la primera nota a pie de página de su versión: «Las aclaraciones entre corchetes y las notas a pie de página son del traductor» $(\mathrm{K}, \mathrm{II})$. Andrew Chesterman (I997: 65) justifica esta práctica como la norma en cualquier traducción que aspire a estar, o que no pueda evitar el permanecer, en estrecho vínculo con la cultura de origen. En la traducción «expuesta» el profesional abandona en principio casi todas las aspiraciones al disfraz, «su artificialidad, su radical carácter de fingimiento, su ineludible condición de impostura, su vocación de representación» (Marías, 2001: 383).

Un elemento estrechamente ligado a la calidad «expuesta» de una traducción es el grado de equivalencia que el traductor alcanza, o aspira a alcanzar. El hallazgo de equivalencias apropiadas es la tarea central de toda traducción (House, 2006: 344). Kovacsics es consciente de las pruebas impuestas por el texto en el que trabaja, y en variadas ocasiones no duda en darnos información extra para comprender el pasaje, «[his] suitable metalanguage»(House, ib.). Su traducción tiene escasas notas a pie de página, lo que se agradece por el lector, y a la misma vez dice de la importancia de las que se hallan.

Un ejemplo: Klemperer nos dice que «en I939 [se] escribían por los caídos unas necrológicas que llenaban todo un recuadro grande» en los periódicos, «y cuando el héroe en cuestión era fabricante o comerciante en la vida civil, su séquito [o plantilla] no se privaba de dedicarle una necrología especial». De «ahí que la hipócrita y sentimental palabra Gefolgschaft [séquito] forme parte de mi repertorio», donde a este segundo corchete sigue la nota número 26: «En el derecho laboral nacionalsocialista, denominación de todos los trabajadores de una empresa, con excepción del jefe» $(\mathrm{K}, \mathrm{I} 83)$. En el original encontramos: «dann ließ es sich seine Gefolgschaft nicht nehmen, ihm von sich aus einen besonderen Nachruf zu widmen [und] so gehört denn auch das gefühlsverlogene Wort 'Gefolgschaft' in mein Repetitorium»(I3I). En español «séquito» es un término asociado 
con los príncipes y nobles feudales, es decir, un conjunto de gente que acompaña al gran personaje en muestra de reverencia y adhesión, o para asistirlo en sus necesidades. No precisamente lo que inspira un capataz o el gerente en una fábrica. Pero en la psicología nacionalsocialista los obreros habrían de ser también secuaces de sus jefes, sus cómplices ideológicos, de ahí la idea del «séquito», clara alusión a un estado de jerarquías. De acuerdo con Robert Michael y Karin Doerr (2002: I78), inicialmente se llamó «Gefolgschaft» al colectivo de los seguidores de Hitler, a una comunidad que acataba ciegamente su voluntad. Luego, por extensión, se amplió a los subordinados de los demás jefes menores de la escala. El traductor se ha decidido por la equivalencia ideológica, para dar a entender a su lector la función política del término en los años del tercer Reich. Consciente del desfase, empero, decide incorporar el original alemán en cursivas, más la adición de los corchetes y la nota a pie de página, para agotar las posibilidades y la validez de su solución.

El mismo Klemperer se ve necesitado de interpretar el caso para sus lectores de 1947. Por ello, primero, nos habla de la «hipocresía afectiva del nazismo, el pecado mortal de la mentira consciente, empeñada en trasladar al ámbito de los sentimientos las cosas subordinadas a la razón, el pecado mortal de arrastrarlas por el fango de la obnubilación sentimental» $(\mathrm{K}, 342)$ [«Die ganze Gefühlsverlogenheit des Nazismus, die ganze Todsünde des bewußten Umlügens der vernunftunterstellten Dinge in die Gefühlssphäre und des bewußten Verzerrens im Schutz der sentimentalen Vernebelung», 251]. Es que, efectivamente, en alemán también el término tiene resonancias feudales, y los nazis revestían Gefolgschaft de «antigua tradición alemana»; convertían a los obreros y empleados en vasallos, en hombres armados, obligados por un juramento de lealtad, «miembros del séquito de los nobles caballeros» $(\mathrm{K}$, 343). Éste es un ejemplo de cómo el traductor, incluso cuando vierte al castellano la explicación de Klemperer, se piensa requerido de añadir los corchetes y la nota a pie de página, aclaratorios. Adan Kovacsics sabe en su página I83 que más adelante, en la 343 de su versión, el mismo texto del original hará por disipar la duda del lector, pero quiere prepararlo para el evidente anacronismo semántico. Así interpreta la interpretación de Klemperer; su papel de traductor «como hermeneuta consiste en ser capaz de comprender incluso lo que le parece extraño e incomprensible, en olvidarse del yo y pasar al nosotros» (Vidal, 1997: 104).

En otro momento similar, Klemperer trata de explicarse entonces, en 1946, la ambigüedad de una de las cantilenas nazis de desfile militar: «Kameraden, die Rotfront und Reaktion erschossen, / Marschiern im Geist in unsern Reihen mit» (26I). Como habría dos traducciones posibles, una en la cual el «Frente Rojo» (die Rotfront) y «la reacción» (die Reaktion) son los agentes del ametrallamiento —éstos [habiendo] aniquilado $a$ los camaradas-, y otra en la cual los camaradas son los que ultiman al Frente Rojo y a la reacción, que son ahora complementos de objeto directo, Klemperer irónicamente se pregunta: ¿quién entre los soldados del coro o entre los espectadores «habrá pensado en estos aspectos gramaticales o estéticos, quién se habrá devanado los sesos preguntándose, en general, por el contenido?» [«Wer von den Marschierenden, wer im Publikum würde wohl an solche grammatischen oder ästhetischen Dinge denken, wer sich wegen des Inhalts überhaupt Kopfschmerzen machen?», 26I]. E1 lector de la versión española, para entender a cabalidad de lo que se habla, necesita de la interpretación añadida por Kovacsics, quien la da gustoso,

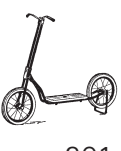

201 
entre paréntesis, como alternativa: «Camaradas que por el Frente Rojo y por la reacción fueron asesinados a tiros (o: que asesinaron a tiros el Frente Rojo y la reacción)...» (K, 356).

Klemperer (2003: 764) habla en I933 del sufrimiento del periodista y escritor Erich Mühsam, asesinado en julio del año siguiente en el campo de concentración de Sachsenhausen (1975: 4I): «Man könnte das Sprichwort variieren und sagen: das Schlechtere ist der Freund des Schlechten» [«Podríamos retocar el refrán y decir: lo peor es amigo de lo malo», $\mathrm{K}$, 6o]. En alemán el refrán original es Das Bessere ist der Feind des Guten, pero Klemperer da por sentado que su lector conoce el original y no lo refiere. El traductor respeta su decisión; el equivalente español iría así: «Lo mejor es (el peor) enemigo de lo bueno», que María Moliner (1998: III3) interpreta como «el hecho de que a veces, por querer mejorar una cosa, se estropea». Aquí falta la nota a pie de página o los socorridos corchetes; la conveniencia del carácter «expuesto» de la traducción no se aprovecha, para una mejor comprensión del original.

\section{LENGUAJE FIGURADO}

La traducción del lenguaje tropológico puede pasar a menudo por un indicador revelador de la pericia del traductor. Peter Newmark (I988: Io4) afirma que la traducción de las metáforas, por ejemplo, es el problema particular más importante para el que acomete la tarea. El lenguaje figurado, argumenta por su parte Esteban Torre (I994: I43), "constituye una prueba de fuego para el traductor». Aunque Klemperer aclara temprano en su texto que quiere componer sus notas «en un sentido filológico literal y no metafórico» $(\mathrm{K}, 25)$ [«so war es denn buchstäblich und im unübertragen philologischen Sinn die Sprache», I6], no podrá evitar o resistirse, aquí o allá, a hablar figurativamente, muchas veces cuando hace uso del sarcasmo o la ridiculización para exponer el carácter irracional del lenguaje retratado, aquel «repugnante caldo de discursos» $(\mathrm{K}, 26)$ [ «der ekelhaften Brühe der Reden", I7].

Kovacsics a veces traducirá las «figuras» estilísticas de Klemperer más o menos directamente, porque el sentido del original casa bien con la intención pragmática de su versión. (véase tabla I)

En otros casos el traductor se ve obligado a buscar otra índole de equivalencia léxica o semántica porque el significado original, aunque comprensible en su traducción literal, no se transfiere naturalmente a la cultura meta, no tiene el mismo significado proposicional (Baker, 1992: 3I). Se procura una substitución cultural, una estrategia que persigue reproducir el impacto logrado en el lector primero; la principal ventaja de usar esta estrategia es que da al lector un concepto con el cual se puede identificar, algo que le es familiar o atractivo (Baker, ib.). La solución está establecida desde hace mucho por la práctica consensuada: «como un coco» (K, $\left.\mathrm{I}_{34}\right)$ para «als schwarzer Mann» (94); «un pez gordo» (K, I83) para «ein wirklich großes Tier» (I3I); «ofensiva de tortuga» (K, 33I) para «Schneckenoffensiven + Schneckentempo» (242).

Mas en otros la solución no está tan a la mano. Kovacsics traduce «als eine Art Knoten im Taschentuch» (15) como «una especie de nudo en la corbata» $(K, 23)$. La idea de Klemperer es que las innumerables siglas a las que el nazismo estaba tan habituado constituían la explicación de las propias suyas, LTI, como el toque final, natural y esperado, de sus reflexiones. «Taschentuch» significa "pañuelo», pero el lector no comprendería la mención de un nudo en el mismo, práctica que es más común 
Tabla I

\begin{tabular}{|c|c|c|}
\hline I & im Gewölk des Nazismus (8) & en los nubarrones del nazismo $\left(\mathrm{K}, \mathrm{I}_{3}\right)$ \\
\hline 2 & mörderische Exil (13) & el exilio asesino $(K, \mathrm{I} 9)$ \\
\hline 3 & $\begin{array}{l}\text { und wie man sich bei uns im Zoologischen } \\
\text { Garten der Judenkäfige ausdrückte (I7) }\end{array}$ & $\begin{array}{l}\text { como nos expresábamos en nuestro jardín } \\
\text { zoológico lleno de jaulas de judíos }(\mathrm{K}, 26)\end{array}$ \\
\hline 4 & frischen, fröhlichen Krieg (33) & la «guerra alegre y refrescante» $(K, 48)$ \\
\hline 5 & an alles gibt man eine Prise Volk (36) & a todo se le agrega una pizca de pueblo $(K, 53)$ \\
\hline 6 & krampfhaften Eifern (59) & invectivas espasmósdicas $(\mathrm{K}, 85)$ \\
\hline 7 & die Fittiche des Todes rauschen (I92) & las alas de la muerte rugen $(K, 26 \mathrm{I})$ \\
\hline 8 & dem Volke aufs Maul sehen (246) & mirarle la boca al pueblo $(\mathrm{K}, 335)$ \\
\hline 9 & wir essen alle aus ein und demselben Topf (257) & comemos todos de una y la misma olla $\left(\mathrm{K}, 35^{\circ}\right)$ \\
\hline
\end{tabular}

en la moda femenina o en la preparación de las servilletas de tela para una cena formal. E1 concepto de corbata no tiene sentido, generalmente, sin el nudo culminante, y las notas de Klemperer sobre el lenguaje nazi tienen en su signo, LTI, su irónica razón de ser, «ein schön gelehrtes Signum, wie ja das Dritte Reich [...] den volltönenden Fremdausdruck liebte» (I5) [«unas siglas de hermosa carga erudita, como las sonoras expresiones de origen extranjero que el Tercer Reich gustaba de utilizar», K, 23].

En otro momento, uno de los compañeros de trabajo de Klemperer en la fábrica se lamenta de la continuación de la guerra y expresa la esperanza de que ésta acabará cuando los aliados comprendan que Alemania es invencible, y que tiene una organización interna envidiable; «wir sind ja so prima organisiert» (IO2), es decir, que los germanos están «organizados de primera». Aunque la idea pudiera entenderse por el lector de habla española, la expresión suena algo inusual; la solución del traductor es «porque estamos organizados de fábula» (K, I45), arreglo informal que casaría bien en el lenguaje de un obrero despierto y en la subsiguiente reflexión de Klemperer al escucharlo: «Prima organisiert - da war es wieder, das eingeschluckte, das umnebelnde Rauschgift» (IO2) [ Organizados de fábula..., he allí, una vez más, ofuscante, la droga absorbida», K I45].

No se comprende de principio por qué Kovacsics se desvía en otros lugares del significado original cuando la circunstancia no lo habría justificado. La estrella judía que debía portar Klemperer a toda hora, desde septiembre de I94I, es a menudo motivo principal de angustia en sus diarios: "Heute vor einem Jahr wurde der Judenstern aufgeheftet. Welch namenloses Elend ist in diesem Jahr über uns gekommen. Alles Vorherige scheint leicht demgegenüber» (I995b: 247) [«Hoy hace un año que me puse la estrella judía. ¡Cuánta desdicha nos ha traído este año! En comparación, todo lo anterior parece leve», 2003b: 248). En LTI se refiere a este tema asimismo: «Nein, alle Einzelfelder reichen nicht aus, die Bitterkeiten des Judensterns zu notieren» (I78). Einzelfeder es traducido por Kovacsics como «detalles de la tela» [ «No, todos 
los detalles de la tela no alcanzan para apuntar todas las amarguras de la estrella judía» (K, 243)], pero el original es más abarcador, alude 204 a los aspectos del tema o la cuestión. "Tela» puede también en castellano significar «asunto o materia», pero es la acepción número once del diccionario de la Academia, y es dable pensar que el lector requeriría de por lo menos once minutos para darse cuenta del significado de la frase, si acaso, tanto así que en ninguna parte del segmento hay una referencia más específica al tejido de la estrella. La idea en alemán es directa, pero en castellano se vuelve bastante ambigua: ¿a qué «tela» aludiría Klemperer? ¿Al material del que se hacía la infame tela o a todo el entramado ideológico detrás de la prescripción?

Una situación similar se da con la traducción de «Lokalpatriotische» (89), «al patriotismo local o consustancial, propio»; Kovacsics se resuelve por «patriotismo de campanario» (K, I26). Una «mentalidad de campanario» pasa por significar una mentalidad mezquina, pero Klemperer habla aquí del tema judío, obsesión suya de la que culpa al nazismo, «única y exclusivamente» (K, I26) [«und nur dessen Schuld», 89]. ¿Cómo entender su referencia a la tragedia de su pueblo como un tópico, como una ruindad de su parte? Es, precisamente, un «tema enorme» (K, I26) («ausreichenden Themas», 89). Justo antes ha recordado cómo los judíos de Dresde fueron a morir en la cámara de gas de Auschwitz: «Sólo quedamos los pocos que vivíamos en matrimonio mixto» $(\mathrm{K}, \mathrm{I} 26)$ [«nur wir paar in Mischehe Lebenden blieben zurück», 89].

Peter Newmark (1998: I07) define la metáfora cliché como la que ha gastado temporalmente su utilidad. El libro de Klemperer también presenta sus clichés en la versión castellana. Algunas

\section{Tabla 2}

\begin{tabular}{|c|c|c|}
\hline I3 & im Ringen um das Herz des Volkes (9) & a la hora de luchar por el corazón del pueblo $(\mathrm{K}, \mathrm{I} 4)$ \\
\hline I4 & Im Granatfeuer des Schlachtfeldes (I3) & En el fuego graneado del campo de batalla $(\mathrm{K}, 20)$ \\
\hline I5 & ein Armutsgelübde (25) & voto de pobreza $(\mathrm{K}, 37)$ \\
\hline I6 & einen festen Willen (46) & voluntad férrea $(\mathrm{K}, 66)$ \\
\hline I7 & $\begin{array}{l}\text { an Herz und Vernunft seiner Hörer wendet } \\
(58)\end{array}$ & $\begin{array}{l}\text { se dirige tanto al corazón como a la inteligencia de } \\
\text { sus oyentes }(\mathrm{K}, 82-3)\end{array}$ \\
\hline I8 & das Brausen der Menge (57) & el bramido de la multitud $(\mathrm{K}, 82)$ \\
\hline I9 & $\begin{array}{l}\text { mit starren Augen und gläubigen Lippen } \\
\text { versicherte (6o) }\end{array}$ & con labios llenos de fe y mirada rígida $(\mathrm{K}, 86)$ \\
\hline 20 & die den Hals frei ließen (I05) & te dejaban libre el pescuezo $(\mathrm{K}, \mathrm{I} 49)$ \\
\hline $2 \mathrm{I}$ & $\begin{array}{l}\text { ihre Gläser [hatten] die betrachteten Dinge } \\
\text { mit rosiger Hoffnung umkleidet (200) }\end{array}$ & $\begin{array}{l}\text { las lentes revestían las cosas observadas con una } \\
\text { esperanza de color de rosa }(\mathrm{K}, 27 \mathrm{I})\end{array}$ \\
\hline
\end{tabular}


de las soluciones son traducciones más o menos literales del original alemán (véase tabla 2).

Pero en otros ejemplos es Kovacsics quien introduce el cliché donde no lo había en el original alemán. $\mathrm{El} 25$ de agosto de 1933 Klemperer anota que la editorial Diesterweg ha rechazado su trabajo «sumamente objetivo y provisto de abundante material» $(\mathrm{K}, 57)$ [ «meine ganz sachliche und stark materialhaltige Arbeit», 39], a pesar de que éste constituía un buen negocio para ellos. Para indicar esta última idea Klemperer usa una metáfora; dice «gefundenes Fressen sein mußte», «debía ser un hallazgo nutritivo», un proyecto que le habría dado ocupación a los obreros de la editorial y a sus agentes de ventas. El traductor convierte este tropo, más o menos original, en «un maná llovido del cielo» $(\mathrm{K}, 57)$, un cliché que abarata un poco la intención original, al tornar ambiguo e irónico lo que no lo parecía.

En otro lugar, Klemperer hace hablar a otro de los compañeros de trabajo en la fábrica, quien se lamenta de que los norteamericanos están prosperando con esta guerra contra Alemania. Dice: «Aber sie werden reich durch den Krieg» (IO3), "que se hacen ricos con la contienda». Kovacsics exagera la condena del hombre y pone en sus palabras otro cliché, esta vez coloquial: «Se forran con la guerra» (K, I45). Después de puntualizar cómo los periódicos hacia el final de la guerra abandonaban ya lo acostumbrado en sus notas necrológicas, a medida que los muertos se hacían más y más abundantes ( Auch der Rahmen um die einzelnen Anzeigen fiel fort», I3I / «se prescindió de los marcos en torno a los anuncios», K r84), Klemperer cierra el pasaje con una imagen compleja, que aúna el hecho de la altísima mortalidad general, la anonimidad de las víctimas y la convención tipográfica donde se agrupa simbólicamente todo el horror:
«Wie in einem Massengrab lagen die Toten in einem einzigen schwarz umzogenen Viereck eng zusammengepackt» (I3I), que podría verterse como «los muertos se apilaban en una fosa común dentro de un único rectángulo bordeado de negro». Es un pasaje metafórico que indica por parte de Klemperer una combinación de amargura, impotencia y, quizás, un poco de mordacidad. Kovacsics añade al verbo «apilarse» una locución adverbial, un cliché, «como sardinas» (K, I84), y con ello consigue eliminar las dos primeras sugerencias, para reforzar la tercera, la del sarcasmo, y vulgarizar el fragmento.

\section{INTENSIFICACIÓN DEL ORIGINAL}

Es interesante cuando el traductor decide desviarse un tanto del significado literal del original, para «ennoblecerlo». Antoine Berman (2000: 29I) apunta que la justificación de este procedimiento la ven sus practicantes en la aparente necesidad de recuperar la brillantez que la prosa del mismo original ha decidido soslayar, decorado que pudiera suplir la oralidad y la retórica, su persuasión y su elocuencia, suprimidas del discurso original. El traductor llena algunos vacíos semánticos que el original «ha dejado» escapar.

Esta intensificación pensamos que sucede en los dos siguientes ejemplos. En el primero Klemperer se refiere al adjetivo "histórico», que «el nacionalsocialismo derrochó a mansalva desde el principio hasta el fin» $\left(\mathrm{K}, \mathrm{72}^{2}\right)$. ¿»A mansalva»? El original dice: «Und hier ist nun das Wort, mit dem der Nationalsozialismus vom Anfang bis zum Ende übermäßige Verschwendung getrieben hat» (5I). «Derrochó a mansalva» se supone que es la traducción de «übermäßige Verschwendung» («derroche excesivo»), pero el traductor equivoca aquí un poco

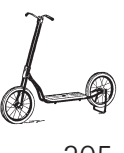

205 
su rumbo. A mansalva es una locución adverbial, derivada de la unión de dos sustantivos, mano y salva, es decir, cuando podemos actuar 206 sin temer represalias; «sin ningún peligro, sobre seguro», lo define el diccionario de la Academia. Asociamos esta locución adverbial generalmente con la violencia, por ello María Moliner (I998: 268) da este ejemplo: «Refiriéndose a la manera de atacar a alguien, de palabra o de obra, con seguridad; sin exponerse, sin peligro. También, con seguridad absoluta de no errar o fallar el golpe». La acepción de algo «en abundancia» es posible aunque bastante rara.

El segundo caso trata de un acto de caridad con doble filo. En la fábrica donde trabaja le regalan a Klemperer una manzana "para su señora esposa, con cordiales saludos» (K, I44). Pero el gesto se echa a perder cuando le preguntan si ella es realmente alemana, aria: «Die Freude am Apfel war hin» (IO2), lo que significa que la alegría por la manzana «se estropeó», o «se jodió» («war hin»). Pero Kovacsics traduce como «la alegría por la manzana se fue al traste» (K, I44), que suena más elegante, mas no transmite con seguridad la frustración del original. Algo similar ocurre en otro ejemplo: «Es hat eine ganze jüdische Horstgeneration gegeben, deren Eltern sich im Betonen und Überbetonen ihres fast schon Teutschtums nicht hatten genugtun können» (86), donde se habla de los padres judíos que buscaban desesperadamente reforzar con matrimonios mixtos la «germanidad» de su descendencia, sin lograrlo en manera satisfactoria («nicht hatten genugtun können»). La traducción de Kovacsics es la siguiente: «Hubo toda una generación de Horst judíos, cuyos padres no daban abasto a la hora de poner énfasis y más énfasis en algo rayano ya en el teutonismo» (K, I22). Nos sorprende el uso aquí de la locución verbal «no dar abasto», pues el sentido ímplicito del original es que la

condición que se buscaba no era fácil lograrla -los hijos eran «híbridos» o Mischlinge de segundo grado (Michael, 2002: 277) - , mientras la locución en castellano se refiere a no tener el rendimiento para producir algo, o la capacidad para cumplir con un encargo o propósito, lo que otorga a la traducción un sentido añadido, el de que la generación de los Horst paría sin descanso hijos y más hijos, en aras de conseguir la "pureza» racial, idea que no está presente en el original.

Klemperer es con probabilidad sarcástico al referirnos la complacencia nazi con el vocablo sangre (manía que copió con el mismo deleite el falangismo en España). El uso y abuso del término y de su metaforismo gastado, se aplicaba en todas las circunstancias "históricas», por ello, «in feierlichen Momenten positiver wie negativer Art muß natürlich das Blut herhalten» (277), es decir, que la «sangre» por supuesto ha de «pagar el pato» [«muß natürlich das Blut herhalten»]. Kovacsics traduce este fragmento así: "Así pues, en los momentos solemnes, sean de carácter positivo o negativo, es preciso poner la sangre sobre el tapete» $(\mathrm{K}, 379)$. La última expresión es coloquial y significa estar discutiéndose, en estudio, pendiente de resolución, asunto que se saca a relucir (Gran Diccionario, I999). Como quiera que sea, es solución más elegante que la del alemán pero, con mucho, menos irónica o mordaz, si es que el lector pudiera siquiera considerarlo así, lo que dudamos.

En otro momento Klemperer llama la atención sobre los anuncios públicos de matrimonios imposibles, «un tipo de enlace matrimonial muy singular» ("eine absonderliche Eheschließung»), de una mujer con su novio caído en la guerra: «Frauen teilten die nachträglich vollzogene Vermählung mit dem gefallenen Verlobten mit» (I3I). Nachträglich sirve aquí de 
adverbio. Kovacsics pone en su lugar un latinismo, «una mujer notificaba la boda celebrada a posteriori con su novio muerto en combate» (I84), algo que tal vez ningún lector encontraría fuera de lugar en un libro escrito por un filólogo, pero que el original no sanciona.

$\mathrm{Al}$ original se le hace también más agresivo en su versión al castellano. Es lo que sucedería en las dos siguientes pautas. Klemperer constata la curiosa hostilidad nazi hacia todas las religiones organizadas, en especial el catolicismo, con el uso por el partido de la simbología cristiana, como el martirologio; como en «Wer an solchen Zeremonien nicht direkt oder durch das Kino teilgommen hat, der ist schon durch den frommen Blutdunst der Ausdrücke allein eingenebelt» (II8). Frommen Blutdunst es «vapor / vaho piadoso de sangre», de manera literal. Figurativamente, quizás podríamos decir «ambiente» o «atmósfera piadosa de sangre». Kovacsics se decide por «A quien no haya participado en estas ceremonias, sea directamente, sea a través del cine, le bastará el tufo a religión y sangre que desprenden estas expresiones» $(\mathrm{K}, \mathrm{I} 66)$. Tufo tiene una denotación bastante clara en español: «Olor molesto / emanación gaseosa que se desprende de las fermentaciones y combustiones imperfectas» (Gran diccionario, 1999), ambas, sin duda, muy apropiadas para las acciones del nazismo, pero tal vez no para el estilo de Klemperer, o su intención, pues, además, la frase tufo a religión es un cliché en castellano.

Por otra parte, insultar a Goebbels, el ministro de propaganda nazi, debe parecer también una tirada normal en un escritor judío como Klemperer; el lector no se sorprendería entonces ante esta frase: "Cuántas veces apunté chistes sobre la jeta y la cara dura de Goebbels» $(\mathrm{K}, 322)$, pero el original es menos concreto, es ambiguo: "Wie oft habe ich in meinem Tagebuch notiert [...] Witze über Goebbels'
Maul und Stirn [lit. «la boca y la frente de Goebbels»]»(236). Maul también admite las siguientes acepciones peyorativas: «morro» y «hocico». Es posible la expresión alemana die Stirn haben, «tener la cara dura». Es un tanto difícil determinar lo que Klemperer pretende decirnos.

\section{ATENUACIÓN DEL ORIGINAL}

Es dado también encontrarse con el efecto contrario: se mitiga la riqueza semántica del original. Berman (2000: 29I) se refiere a este recurso como «qualitative impoverishment», la traducción silencia la riqueza icónica del texto de origen.

En castellano, el uso de las locuciones adverbiales puede otorgar un aire pintoresco, doméstico o coloquial - a veces vulgar-, a la expresión escrita. Ahora el original se «deprecia», por así decirlo. Es lo que ocurriría en los siguientes ejemplos: (véase tabla 3)

Este proceso de «desvalorización» textual puede ocurrir de manera similar con las frases verbales, como en: (véase tabla 4)

En otras oportunidades el traductor se resuelve a reducir o neutralizar la magnitud del impacto semántico, en aras de conseguir un estilo más formal o, en su opinión, estéticamente hermoso. Así generaliza - traduce por medio de un hiperónimo un término relacionado de sentido más abarcador - cuando vierte la frase «ein hüpfender Backfisch» (II3), ¿una «pollita» o «chiquilla retozona»?, por «adolescente saltarina» (I59). Klemperer se refiere a una antigua compañera de trabajo, Paula von B., «ayudante de cátedra en el departamento de Filología Alemana» (K, 157$)$, la cual «trabajaba feliz y contenta» bajo el régimen de los nazis. En una ocasión, en I933, cuando Klemperer le recrimina ese estado de euforia en un momento en que 


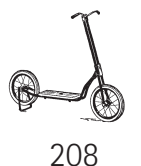

\begin{tabular}{|c|c|c|}
\hline 22 & $\begin{array}{l}\text { se incoan con mucho bombo procesos } \\
(\mathrm{K}, \mathrm{I} 66)\end{array}$ & $\begin{array}{l}\text { por «führt man aufgebauschte [inflados] Prozesse» } \\
\text { (II8) }\end{array}$ \\
\hline 23 & hacía hincapié $(\mathrm{K}, \mathrm{I68})$ & $\begin{array}{l}\text { por «unterstrichen [subrayado, puesto de relieve, } \\
\text { acentuado] hat» (II9) }\end{array}$ \\
\hline 24 & $\begin{array}{l}\text { Luego, a duras penas, bajando la vista... } \\
(\mathrm{K}, \mathrm{I} 78)\end{array}$ & $\begin{array}{l}\text { por «Dann, mühselig [laboriosamente, con dificultad], } \\
\text { mit gesenkten Augen» (I27) }\end{array}$ \\
\hline 25 & dar rienda suelta $(\mathrm{K}, \mathrm{I} 82)$ & por «Luft machen [airear, divulgar] möchte» (130) \\
\hline 26 & le viene realmente de perillas $(\mathrm{K}, \mathrm{I} 96)$ & $\begin{array}{l}\text { por «wahrhaftig am Platze ist» [aprox. está } \\
\text { verdaderamente en su lugar] (I40) }\end{array}$ \\
\hline 27 & se manifestaba sin tapujos $(\mathrm{K}, 339)$ & por «hier tat sich ganz unverhüllt [ descubierto]» (249) \\
\hline
\end{tabular}

\section{Tabla 4}

\begin{tabular}{|c|c|c|}
\hline 28 & hace sus primeros pinitos $(\mathrm{K}, 205)$ & por «beginnt» [comenzó] (I48) \\
\hline 29 & $\begin{array}{l}\text { este apartado es rico en expresiones y fórmulas } \\
\text { oficiales, que todos los afectados conocían } \\
\text { hasta la saciedad }(K, 245)\end{array}$ & $\begin{array}{l}\text { por «diese Sparte ist reich an amtlichen Ausdrücken } \\
\text { und Wendungen, die allen Betroffenen geläufig waren } \\
\text { [estaban familiarizados]» (I80) }\end{array}$ \\
\hline 30 & $\begin{array}{l}\text { y me tomará por un hipócrita empeñado en } \\
\text { hacerle la pelota }(K, 266)\end{array}$ & $\begin{array}{l}\text { por «und hält mich für einen Heuchler, der sich } \\
\text { anschmieren }[\text { timar }] \text { will» (196) }\end{array}$ \\
\hline $3 \mathrm{I}$ & $\begin{array}{l}\text { ¿para qué seguir enumerando todo cuanto se } \\
\text { había ido al garete? }\left(K, 35^{8}\right)\end{array}$ & $\begin{array}{l}\text { por «aber wozu immer wieder weiter aufzählen, was } \\
\text { alles schon fehlgeschlagen [fracasado] war?» (262) }\end{array}$ \\
\hline
\end{tabular}

a sus colegas y a los profesores los humillan, cuando prohíben o incineran obras que ella «apreciaba hasta hace ese momento», cuando reniegan los nazis de todas las creaciones del espíritu que ella hasta ahora también veneraba, Paula lo interrumpe «un tanto desconcertada», $y$ «con tono sumamente cariñoso» le asegura que está demasiado nervioso y que debe tomarse unas semanas de vacaciones durante las cuales no debe leer ningún periódico. Todo eso que Klemperer lamenta son para ella «minucias y borrones inevitables en estos grandes cambios». Paula se marcha entonces como llegó, risueña y ligera. Cuando Klemperer la describe como «una pollita retozona» claramente quiere connotar negativamente la frivolidad de la mujer. Aunque «pollita» pasa por palabra afín de «niña» en España, el sentido que un lector hispanoamericano recogería sería otro, el de una muchacha sin mucha distinción, idea que sí está presente en el adjetivo, «retozona», como de alguien poco serio, dado a veleidades, con pocos dedos de frente. Paula von B. sale sin duda mucho mejor parada con la traducción «adolescente saltarina» (I59) 4 .

Otro ejemplo sucede en la página 279 de la traducción; Klemperer nos describe a algunos

4 El término Backfisch se remonta al siglo XVII, en la jerga de los estudiantes alemanes, para designar a una chica adolescente entre I4 y I6 años. Aquellos tomarían la palabra de los pescadores, que distinguían entre peces de escamas delicadas y los de escamas ásperas a la hora de cocinarlos (Back significa «mejilla» en alemán) (Kluge, I895: 19, 7I). La analogía con «pollita» parece, entonces, justificada. 
de sus compañeros de trabajo judíos en la fábrica y cuando llega al dentista, «o mejor dicho, el «terapeuta dental» («Zahnbehandler»), anota que era un hombre terriblemente locuaz con sus pacientes indefensos, y Klemperer inserta entre guiones una pregunta irónica: «¿Qué puede uno contestar con la boca abierta de par en par?». El pasaje en alemán es el siguiente: «Was soll man bei aufgeschraubtem Munde entgegnen?» (205), es decir, aprox., «¿qué podría uno replicar con la boca dislocada» [《desatornillada»]? Klemperer se burla gentilmente de su compañero de infortunio, pero el traductor ha eliminado la connotación chistosa al decidirse por la traducción mencionada (K, 279).

Cuando Klemperer habla de los autos de carrera y de sus pilotos nazis, «hinter dem Lenkrad ihres Kampfwagens» (Io), el traductor opta por convertir el último término compuesto (Kampfwagens, «vehículos militares») en «bólidos»; su solución («al volante de sus bólidos», K, I6) tal vez otorga un mayor sentido poético a la frase, a la vez que mantiene la connotación de empuje y velocidad en la palabra alemana, pero la intención irónica del original se ha perdido. Kovacsics le ha quitado el aguijón a aquella.

\section{TRADUCCIÓN DE LOS DIÁLOGOS}

Klemperer utiliza el recurso del diálogo para presentar algunas de las situaciones que ilustran sus puntos de vista, lo que otorga a su escrito una arista más de heterodoxia; texto un tanto ensayo académico, otro tanto memoria, un tanto alegato, un tanto anatema, otro tanto relato, y más. Su uso del diálogo recuerda en ocasiones el de Camilo José Cela en sus crónicas periodísticas. En estas conversaciones intercaladas participan alemanes de variados niveles culturales de educación (militares, gente ficticia, oficiales de la Gestapo, catedráticos, compañeros de turno en la fábrica, alemanes de religión judía, mujeres, hombres, niños...). Sería en los diálogos de los «personajes» humildes, los del pueblo menos educados, donde la destreza de un traductor debe mostrarse, pues sería natural el uso de un lenguaje popular (localismos, slang) en sus parlamentos. Por lo general Kovacsics sale exitoso en la tarea y los diálogos fluyen con naturalidad; se muestra su práctica en la traducción de otros narradores de expresión alemana. A veces, sin embargo, el traductor se vería obligado a presuponer. En el capítulo xvir le dice un carpintero al autor, en el verano de 1935: "Ich schwitze! In der Systemzeit gab es die schönen Schillerkragen, die den Hals frei ließen» (IO5), que Kovacsics traduce como «iEstoy sudando! En la época del sistema existían aquellos hermosos cuellos al estilo Schiller que te dejaban libre el pescuezo» (K, I49); en tiempos del poeta alemán, hacia finales del siglo Xviı, simbolizaba rebeldía, una señal de libertad personal. Klemperer usa el vocablo «Hals», que significa «cuello», pero también «gaznate», o pescuezo. Es lo que se supondría nos diría un carpintero, al arreglarnos la puerta del jardín. Tal vez, aunque sospechamos que pocos carpinteros usarían a Schiller en su repertorio diario con la seguridad de este. Incluso en Alemania. Juzgando por el resto de la expresión, nos parece que "garganta» - para no repetir «cuello»— era más natural que «pescuezo». El carpintero luego añade que «So was hat man jetzt nicht mehr, immer nur enges Zeug und womöglich steifes» (IO5) [ «Ahora ya no existen, sino sólo cosas estrechas y, a ser posible, rígidas», K I49]. Es obvio que el lenguaje del carpintero, como quiera que fuere entonces, ha pasado por el filtro del filólogo Klemperer, y es este texto filtrado con lo que cuenta el traductor.

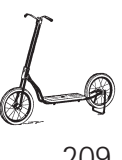

209 


\section{LA IRONÍA DE KLEMPERER}

Cuando su tema es el lenguaje nazi, Klem210 perer querrá desconstruir las pretensiones de este, la «enumeración de los éxitos propios» (K, 320) [ «das Aufzählen der eigenen Erfolge», 235]. Hará uso de «esa ironía judía tan odiosa para el nazismo puesto que cuestionaba la hipocresía sentimental» $(\mathrm{K}, 353)$ [«jene jüdische Ironie, die dem Nazismus so verhaßt war, weil sie Gefühlsheucheleien zu Leibe rückt», 259]. Su uso de la ironía en los diarios y en LTI podría tomarse como paradójica, desde el punto de vista de que la ironía ofrece al lector más de un mensaje para la codificación, y esta duplicación del mensaje quiere esconder la intención del autor de la interpretación inicial (Rose, I993: 87). Mas, seguramente, el propósito de Klemperer es que sus lectores alemanes, o potenciales, lo comprendan sin estas trabas o velos semánticos. El quid es que Klemperer no aspira a ser irónico con el lector sino con los personajes de su relación, y con sus acciones - como si ellos fueran también parte del nuevo público, a la vez que forman parte del escenario-, para el mismo beneficio de este lector y, posiblemente, de sí mismo, para quien esta larga confesión o testimonio es como una vasta catarsis. Por ello ha de asumir implícitamente que el lector sabrá en todo momento cuándo es irónico y cuándo no lo es. Es un riesgo que toma, pero quizás uno inevitable: como han demostrado Herbert Colston y Raymond Gibbs (2002: 57), a la gente le toma más tiempo comprender un enunciado que tenga una intención irónica que uno con una metafórica. Para el traductor el peligro es desatender a veces esa ironía del original, en aras de conseguir otro propósito que no estaba presente en aquel. «Adolescente saltarina» (K, I59) es, con probabilidad, una versión acepta- ble de «ein hüpfender Backfisch» (II3), pero no sería tal vez la equivalencia indicada. La ambigüedad del original se ha multiplicado innecesariamente en la traducción al español y se habría perdido la ironía del pasaje, la solución del acertijo para el pensador danés Søren Kierkegaard (I999: 75), quien afirmaba además que la ironía empeña en aislarse, pues no desea que se la entienda de manera ordinaria; es un lenguaje para iniciados.

Mediante la ironía Klemperer busca liberarse de las ataduras lingüísticas que lo sujetan al pasado nacional reciente, por eso puede decir Kierkegaard (op. cit. 83-4) que también «el ironista se desata» de sus demonios, cuando por medio de ese lenguaje irónico consigue una «mirada segura frente a lo torcido, lo equivocado, lo vano de la existencia», que le toca al primero en I946. Así recuerda Klemperer la aparatosidad nazi, como una «extraña insensibilidad de los nazis a la comicidad satírica a la que ellos mismos se exponían; ¡uno querría creer en su inocencia subjetiva!» (K, 70-I) [«Merkwürdige Fühllosigkeit der Nazis gegen satirische Komik, der sie sich selbst aussetzen; man möchte bisweilen wirklich an ihre subjektive Unschuld glauben!», 49-50]. O cuando trata del archiusado adjetivo "histórico» como de un cliente maltratado por sus usuarios: «In wieviel Schlagzeilen, in wie vielen Leitartikeln und Reden ist das Wort gebraucht und um seinen ehrwürdigen Klang gebracht worden! Man kann ihm gar nicht Schonung genug angedeihen lassen, wenn es sich erholen soll» (5I) [ «En cuántos titulares, en cuántos editoriales y discursos se usó la palabra, que quedó despojada de su venerable resonancia! Necesitará todos los cuidados imaginables para recuperarse», 72]. Los nazis también hacían amplio uso de la ironía en 
Tabla 5

\begin{tabular}{|c|c|c|}
\hline 32 & $\begin{array}{l}\text { immer einigermaßen im Verdacht der } \\
\text { Schaumschlägerei (57) }\end{array}$ & $\begin{array}{l}\text { siempre está bajo la sospecha de ser pura bambolla } \\
(\mathrm{K}, 82)\end{array}$ \\
\hline 33 & $\begin{array}{l}\text { gar bloß Schaumschlägerischen zu verlieren } \\
\text { (II2) }\end{array}$ & perderse $[\ldots]$ peor aún, en meras bambollas $\left(K,{ }_{15} 8\right)$ \\
\hline 34 & $\begin{array}{l}\text { ist vielleicht bisweilen um einen Finger breit } \\
\text { (III) }\end{array}$ & se desviaba quizá un pelín (K, I57) \\
\hline 35 & $\begin{array}{l}\text { das trifft auch nicht den Kern der Sache } \\
\quad(2 \mathrm{I} 3)\end{array}$ & no da en el clavo $(K, 29 I)$ \\
\hline 36 & $\begin{array}{l}\text { so hatte ich dabei den Satz im Ohr, denn der } \\
\text { Generalissimus Brauchitsch seinerzeit zur } \\
\text { Würze eines Armeebefehls machte (233) }\end{array}$ & $\begin{array}{l}\text { recordé la frase que el generalísimo Brauchitsch } \\
\text { convirtió en su día en sal y pimienta de una } \\
\text { orden del ejército }\left(\mathrm{K}, 3^{\mathrm{I} 8}\right)\end{array}$ \\
\hline 37 & bis zum Verrecken! (IO3) & hasta palmarla (K, I45) \\
\hline 38 & $\begin{array}{l}\text { etwas Gestohlenes und Erschobenes habt ihr } \\
\text { ja immer bei euch (183) }\end{array}$ & $\begin{array}{l}\text { que siempre llevas encima algo robado o } \\
\text { conseguido por algún chanchullo }(\mathrm{K}, 250)\end{array}$ \\
\hline 39 & Wegtreten, dalli! (I84) & ¡Fuera de aquí, pero volando! $(\mathrm{K}, 250)$ \\
\hline
\end{tabular}

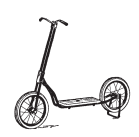

211 su propaganda, mediante el entrecomillado $(\mathrm{K}, 208)$ y Klemperer rememora cuando le quitaron todo acceso a las bibliotecas de Dresde, que quedaban estas «a buen recaudo» («sichergestellt», 15I) de los peligrosos judíos, «denn die Beauftragten der Partei stehlen und rauben nicht» (151) ["pues los encargados del Partido no hurtan ni roban», K 209]. En estos pasajes el lector español puede captar la ironía del original de inmediato, aque1la burla que según Kierkegaard (1999: 84) se oculta en o tras la seriedad, «y su seriedad en burla».

La función de las frases idiomáticas en Klemperer tiene también, en ocasiones, una fuerte carga irónica o sarcástica, ya sea para referirse a su situación personal, de erudito sin acceso a bibliotecas («saß ich ja im Dresdener Japanischen Palais wie die Made im Speck», I7 / «el Palacio Japonés de Dresde me venía como anillo al dedo», K 26), o para remedar la impronta vulgar del discurso nazi: «Der Jude ist der wichtigste Mann in Hitlers Staat [...] er ist der volkstümlischste Türkenkopf und Sündenbock» (187) [«el judío es el hombre más importante en el Estado de Hitler: es la cabeza de turco y el chivo expiatorio más popular», 254]. En los siguientes ejemplos, Kovacsics consigue hallar la equivalencia semántica del idiomatismo original (véase tabla 5).

En el caso de «Der Judenrummel [...] Aber der Rummel tat doch seine Wirkung» (48), la traducción de rummel conseguiría con un lector genérico tal vez mayor resonancia de haberse escogido la equivalencia «jaleo», que es palabra reconocida en muchos países de habla española; Kovacsics decide traducirlo por «follón», que probablemente sólo tiene curso en España: «El follón con los judíos [...] Pero el follón surtió efecto» $(\mathrm{K}, 69)$. 


\section{CONCLUSIONES}

Kovacsics se ha propuesto reproducir en su traducción la calidad de aviso y recordatorio en los que se constituye el tratado de Klemperer, sobre todo por la pertinencia que tiene en cuanto al siempre latente y siempre peligroso uso del lenguaje por los totalitarismos. La intuición de Kovacsics le lleva a decidirse por una traducción «expuesta», pues tiene en cuenta seguramente la naturaleza de las razones que aconsejan la traducción del texto de Klemperer en primera instancia, y, además, a su lector potencial o implícito. Este tipo de traducción Juliane House (200r: 252) lo ve justificado para lo que ella llama en una ocasión «sacrosanct document $[\mathrm{s}]$ », y en otra «timeless originals» (2006: 347). El traductor está consciente de que su versión requiere un nuevo marco de referencia, pues aquélla sale a la luz en un lenguaje diferente, en una comunidad cultural y lingüística disímil de la del original, de modo que se hace necesario un cambio en la órbita del discurso: se permite a los lectores, los miembros de la cultura meta, el asomarse indiscretamente a las interioridades del proceso, aunque sea «a distancia». En la traducción «expuesta», escribe House, la labor del traductor es importante y es visible. Puesto que su responsabilidad, asumida, es la de ofrecer a esos lectores acceso al texto original, y la posibilidad de experimentar el mismo impacto que los lectores primeros, los de la cultura de origen, el traductor les otorga el puesto de observadores, para que juzguen el resultado «desde fuera» (200I: 250).

El traductor de LTI no es enteramente consecuente o coherente en su desempeño. Hemos citado algunos ejemplos de cómo, al ocuparse de trasvasar el lenguaje figurado, Kovacsics en ocasiones se desvía de su cauce propuesto, para conseguir localmente efectos individuales que, pensamos, no casan bien con el original, o con el procedimiento adoptado en principio. También se consideraron las circunstancias cuando el traductor intensifica o atenúa el significado del original. La traducción «expuesta» tiene en su base una orientación pragmática, la cual se diluye un tanto en estos accidentes. En ellos Kovacsics se mueve hacia la otra dimensión, hacia la traducción "cubierta», covert translation, la que busca en esencia reproducir la función (de la metáfora, del cliché, del modismo) pero no su intención o su motivación; es cuando el traductor hace primar el cómo sobre el por qué. Juliane House (200r: 250) también nos recuerda que este tipo de traducción, la «cubierta», es más engañosa que la otra, pues su equivalencia funcional se puede manipular más fácilmente. No en balde el sentido de covert en inglés es afín al de lo furtivo en castellano, lo que se hace a escondidas.

En la nota de la contratapa en la versión en español de LTI, se nos habla de la excepcionalidad del libro de Klemperer, de su «brillante crítica», del «impresionante ensayo», de cómo representa la «principal referencia de toda reflexión acerca del lenguaje totalitario»y de cómo en el texto «se pone de manifiesto el don de este filólogo alemán para plantear cuestiones complejas de forma apasionante y amena». Aunque estas notas quieren muchas veces asegurar al posible comprador sobre la calidad y trascendencia del libro que está por adquirir, ¿podrían los editores de Minúscula apelar a toda esta excelsa calificación con confianza si también no incluyeran automáticamente la traducción en ese panorama? Sin duda que no, y nosotros nos atenemos no sólo a la caracterización del original de Klemperer sino también a la de su traducción, porque las inconsistencias o discrepancias que hemos señalado no significan un restar de la 
calidad general de la versión de Kovacsics ${ }^{5}$. Su traducción, como la de cualquier actividad intelectual, la ha realizado en solitario, pero su existencia, al decir de Lawrence Venuti (I998: 4), «links multitudes, often in the most unexpected groupings».

RECIBIDO EN MAYO 2008 ACEPTADO EN ENERO 2009

5 Una omisión importante debería subsanarse en la próxima edición, para crédito de ambos, el traductor y la editorial. Hay un poema de Klemperer al principio del capítulo xxıv. Sabemos que esta composición -mediocre artísticamente- es de su autoría porque nos lo dice justo antes: «Ich habe ein paar Verse gedrechselt, die ich ihnen schicken will» («He modelado un par de versos que les enviaré a ellos»). Klemperer está hablando del matrimonio de Walter y Grete Blumenfeld, que había embarcado desde Francia hacia Perú en I935 (2003: 217). Inexplicablemente, esta importantísima aclaración sobre la autoría del poema no aparece en la traducción al español. El lector queda totalmente desorientado. Se lee lo siguiente: «Y en vez de alegrarse se quejan de los mareos y de su nostalgia por Europa» (23I) y luego sigue el poema. El lector habría de preguntarse de quién es el poema y a esa hora estaría buscando en el índice, de haberlo, cualquier indicación que explique su procedencia, sin lograrlo.

\section{OBRAS CITADAS}

Baker, Mona (1992). In Other Words. A Coursebook on Translation. New York: Routledge.

Barbe, Katharina (2007). "Victor Klemperer - the accidental sociolinguist», en Journal of Sociolinguistics, $\mathrm{II} / 4, \mathrm{pp}$. 505-520.

Benites-Dumont, Andrea (s.d.). «24 de marzo de I976 - 24 de marzo de 2007: Hay un antes y un después». <http://www.nodo5o.org/codoacodo/ turca.htm> [Consulta: 28 de abril, 2008.]

Berman, Antoine (2000). «Translation and the Trials of the Foreign». En Lawrence Venuti (ed.). The Translation Studies Reader. Londres: Routledge, pp. 284-297.

Chesterman, Andrew (1997). Memes of Translation: The spread of ideas in translation theory. Amsterdam / Philadelphia: John Benjamins.

Colston, Herbert L., y Raymond W. Gibbs, Jr. (2002). «Are Irony and Metaphor Understood Differently?». Metaphor and Symbol, I7/1, pp. 57-80.

Díaz, Duanel (s.d.). «Estudiarla para destruirla» <http:/www.cubaencuentro.com> [Consulta: I7 de enero, 2008.]

Fischer-Hupe, Kristine (20oI). Victor Klemperers «LTI. Notizbuch eines Philologen»: ein Kommentar. Hildesheim: Georg Olms Verlag.

Gran diccionario usual de la lengua española (I999). Barcelona: Larousse.

House, Juliane (200I). «Translation Quality Assessment: Linguistic Description versus Social Evaluation». Meta: Translator's Journal, 46/2, pp. $243-257$.

- (2006). "Text and Context in Translation.» Journal of Pragmatics, 38, pp. 338-58.

Kierkegaard, Søren (I999). «Sobre el concepto de la ironía». Trad. de Darío González. Revista de Occidente, 22I, pp. 72-86.

Klemperer, Victor (1975). LTI. Notizbuch eines Pbilologen. Leipzig: Reclam Verlag.

- (I995a). Ich will Zeugnis ablegen bis zum letzten. Tagebücher 1933-I94I. Walter Nowojski (ed.), con la colaboración de Hadwig Klemperer. Berlín: Aufbau-Verlag.

(1995b). Ich will Zeugnis ablegen bis zum letzten. Tagebücher 1942-I945. Walter Nowojski (ed.), con la colaboración de Hadwig Klemperer. Berlín: Aufbau-Verlag. 


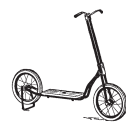

- (200I). LTI. Apuntes de un filólogo. Trad. de Adan Kovacsics. Barcelona: Editorial Minúscula. - (2003a). Quiero dar testimonio hasta el final. Diarios 1933-I94I. Trad. de Carmen Gauger. Barcelona: Galaxia Gutemberg.

- - (2003b). Quiero dar testimonio hasta el final. Diarios 1942-I945. Trad. de Carmen Gauger. Barcelona: Galaxia Gutemberg.

Kluge, Friedrich (1895). Deutsche Studentensprache. Strassburg: Karl J. Trübner.

Marías, Javier (200I). «La traducción como fingimiento y representación». En Literatura y fantasma. Madrid: Alfaguara, pp.383-392.

Michael, Robert, y Karin Doerr (2002). NaziDeutsch/Nazi German. An English Lexicon of the Language of the Third Reich. Westport, Conn.: Greenwood Press.

Moliner, María (I998). Diccionario del uso del español. Tomos I y II. Segunda edición. Madrid: Gredos.

Moreno León, Javier (s.d.). «La tiranía cotidiana». $<$ http:/www.ojosdepapel.com/ show_article. aspx?article_id=2069> [Consulta: 17 enero 2008.]

Newmark, Peter (1988). A textbook of translation. New York: Prentice Hall International.

Rose, Margaret A. (1993). Parody: ancient, modern, and post-modern. Cambridge University Press.

Torre, Esteban (1994). Teoría de la traducción literaria. Madrid: Editorial Síntesis.

Venuti, Lawrence (1997). The Scandals of Translation. Towards an ethics of difference. Londres: Routledge.

Vidal Claramonte, M. ${ }^{a}$ Carmen África (1997). «El traductor como hermeneuta». En Esther Morillas y Juan Pablo Arias (eds.). El papel del traductor. Salamanca: Ediciones Colegio de España,pp. I03-IO8.

Watt, Roderick H. (I998). "Victor Klemperer's 'Sprache des vierten Reiches': LTI = LQI?» German Life and Letters, 51/3, pp. 360-371. 